\title{
How Do I Reverse Oral and Parenteral Anticoagulants?
}

\section{Wie Reversiere ich die Wirkung von Oralen und Parenteralen Antikoagulanzien?}

\author{
Jürgen Koscielny ${ }^{1}$ Edita Rutkauskaite ${ }^{1}$ Christoph Sucker ${ }^{2}$ Christian von Heymann ${ }^{3}$ \\ ${ }^{1}$ Charité, Universitätsmedizin Berlin, Gerinnungsambulanz mit \\ Hämophiliezentrum im Ambulanten, Gesundheitszentrum (AGZ), \\ Berlin, Germany \\ ${ }^{2}$ Gerinnungszentrum Berlin Dr. Sucker, Berlin, Germany \\ 3 Klinik für Anästhesie, Intensivmedizin, Notfallmedizin und \\ Schmerztherapie, Vivantes Klinikum, Im Friedrichshain, Berlin, \\ Germany \\ Hämostaseologie 2020;40:201-213.

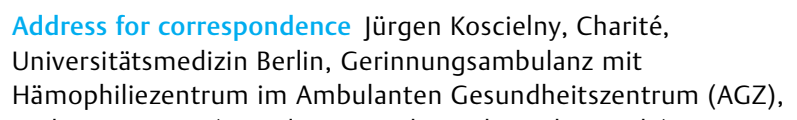

Address for correspondence Jürgen Koscielny, Charité, Universitätsmedizin Berlin, Gerinnungsambulanz mit Hämophiliezentrum im Ambulanten Gesundheitszentrum (AGZ), \\ Berlin, Germany (e-mail: juergen.koscielny@charite.de).
}

\section{Abstract}

Keywords

- oral and parenteral anticoagulants

- reversal strategy

- vitamin K antagonist

\section{Zusammenfassung}

An understanding of reversal strategies alone is important to safely and effectively care for patients in cases of bleeding or invasive procedures. The recent diversification in the number of licensed anticoagulants makes an understanding of drug-specific reversal strategies essential. Intravenous or oral vitamin $\mathrm{K}$ can reverse the effect of vitamin $\mathrm{K}$ antagonists (VKAs) within 12 to 48 hours and is indicated for any bleeding or an international normalized ratio $>10$ or 4.5 to 10 in patients with additional risk factors for bleeding. Furthermore, an additional administration of prothrombin complex concentrate (PCC) may be necessary in cases of major bleeding related to VKA. Protamine (chloride or sulfate) fully reverses the effect of unfractionated heparin and partially in low-molecular-weight heparin. Idarucizumab has been approved for dabigatran reversal, whereas andexanet alfa is approved for the reversal of some oral factor Xa inhibitors (apixaban, rivaroxaban). PCC seems to enhance the haemostatic potential for the reversal of the effect of FXa-inhibitors. So far, there are promising but only limited data on the efficacy of this approach available. Each reversal strategy needs an adequate management beyond the hemostatic treatment (volume replacement, stabilization of homeostasis, e.g., $\mathrm{pH}$ and temperature, resumption of anticoagulation after successful treatment of bleeding, etc.) that is crucial for the successful management of acute bleedings, urgent high-risk surgery, thrombolytic therapies or thrombectomies as well as overdosing of anticoagulants.

Das Verständnis für spezifische Reversierungsstrategien antikoagulierter Patienten ist wichtig, um einen Patienten sicher und effektiv bei Blutungen oder invasiven Prozeduren behandeln zu können. Auf Grund der Vielzahl von Antikoagulanzien ist das Wissen um spezifische Reversierungsstrategien essentiell. Intravenös oder oral verabreichtes Vitamin K kann die Wirkung von Vitamin-K-Antagonisten (VKA) innerhalb von 12 bis 48 Stunden reversieren und ist bei jeder Blutung, bei einer international normalized ratio (INR) $>10$ oder einer INR von 4,5 bis 10 und weitere Risikofaktoren für Blutungen, received

December 9, 2019

accepted

February 9, 2020 (c) 2020 Georg Thieme Verlag KG Stuttgart · New York
DOI https://doi.org/

10.1055/a-1113-0557. ISSN 0720-9355. 


\author{
Schlüsselwörter \\ - Orale und \\ parenterale \\ Antikoagulanzien \\ - Reversierung \\ - Vitamin K \\ Antagonist
}

indiziert. Zusätzlich kann eine Gabe von Prothrombin-Komplex-Konzentraten (PPSB) bei großen Blutungen unter VKA erforderlich werden. Protamin(-chlorid oder -sulfat) heben die Wirkung von unfraktioniertem Heparin (UFH) vollständig und niedermolekularem Heparin (NMH) partiell auf. Idarucizumab ist zugelassen für die Reversierung von Dabigatran, während Andexanet alfa für die Reversierung einiger oraler Faktor Xa Inhibitoren (Rivaroxaban, Apixaban) bedingt zugelassen ist. PPSB scheint eine Erhöhung des hämostatischen Potenzials zu bewirken, welches einen der Reversierung der FXa-Inhibitoren ähnlichen Effekt aufweist. Zur Effektivität dieser Therapie sind bislang viel versprechende, aber insgesamt nur wenige Daten vorhanden. Jede Reversierungsstrategie benötigt ein über die Aufhebung der Antikoagulation hinausgehendes Management (Volumenersatz, Aufrechterhaltung der Homöostase, z.B. pH, Temperatur, Wiederbeginn der Antikoagulation nach erfolgreicher Therapie der Blutung, etc.), welches für die erfolgreiche Behandlung akuter Blutungen, dringender Operationen mit hohem Risiko, avisierter Thrombolysen oder Thrombektomien sowie Antikoagulanzienüberdosierungen unerlässlich ist.

\section{Introduction}

Since the first clinical use of the vitamin $\mathrm{K}$ antagonist (VKA) dicumarol in $1938,{ }^{1}$ the number of indications for the use of anticoagulants has steadily increased. ${ }^{2}$ The anticoagulant effect of available anticoagulants differs depending on the mode of action and the target within the coagulation system ( - Fig. 1). Any anticoagulant treatment increases the risk of spontaneous bleeding and the risk of bleeding during surgery and interventional procedures. Therefore, it is necessary to reverse the effects of anticoagulants in certain clinical scenarios, but usually not in elective surgery:

- Uncontrolled bleeding in the presence of anticoagulants.

- Emergency surgery in the presence of anticoagulants.

- Excessive overdose of anticoagulants without bleedings.

The decision for a targeted reversal of the anticoagulant effect should be made very carefully considering the current clinical situation. Therefore, the potential advantage resulting from the control of bleeding or a reduction of the perioperative bleeding risk should always be weighed against potential harm, in particular the risk of thromboembolism. All reversal strategies usually require a multimodal approach in acute bleeding and are not considered to be the sole therapeutic step. $^{3-9}$ Before reversal, knowledge of the different plasma half-lives and the metabolism and elimination of the different anticoagulants is mandatory ( - Table 1 ). A combination of specific reversal agents with prothrombin complex concentrates (PCCs) should be avoided, whenever possible.

In this review, the current options for reversing different anticoagulants, such as VKA, direct oral anticoagulants (DOACs), and parenteral anticoagulants, are presented.

\section{Treatment of Anticoagulant-Induced Bleedings-General Considerations}

Cases of only clinically mild bleedings without hemodynamic compromise or transfusion requirements usually require med- ical monitoring of these patients and, at least transient, discontinuation of the anticoagulant only. Here, a predominantly clinically oriented procedure is indicated and monitoring of the vital functions on an intermediate care unit may be considered. First, the extent of bleeding should be clinically verified before specific hemostasis management is administere ${ }^{3-9}$ :

- Heavy bleeding in preformed body cavities (e.g., pleura, abdomen).

- Heavy organ bleeding with impending organ failure.

- Severe compartmental bleeding, especially in the extremities.

- Heavy bleeding into the cervical soft tissue with threatening suffocation.

- Intracerebral bleeding.

In the case of an anticoagulant-induced bleeding, the following considerations are crucial for a safe and effective administration of the reversal therapy ( - Fig. 1, - Table 1 ):

- Which anticoagulant was taken?

- When was the last intake of the anticoagulant?

- What is the assumed plasma level of used anticoagulant (peak or trough)?

- How is the kidney and/or liver function?

A basic laboratory and specific coagulation test of the used anticoagulant before and after treatment may be helpful and should follow these considerations ( - Table 2). Special laboratory analysis is particularly indicated for patients with known renal or hepatic insufficiency, which may cause prolonged elimination of the anticoagulant, as well as prior to major surgery. Furthermore, it should be noted that drug interactions may significantly affect anticoagulant plasma levels (www.wechselwirkungscheck.de/index.php). The use of factor concentrates or antidotes is not indicated for mild, as opposed to life-threatening, bleeding. ${ }^{3-9}$

As pointed out earlier, the use of factor concentrates or antidotes is not indicated for mild, as opposed to life-threatening, bleeding. ${ }^{3-9}$ For these clinical scenarios, a wait and see 


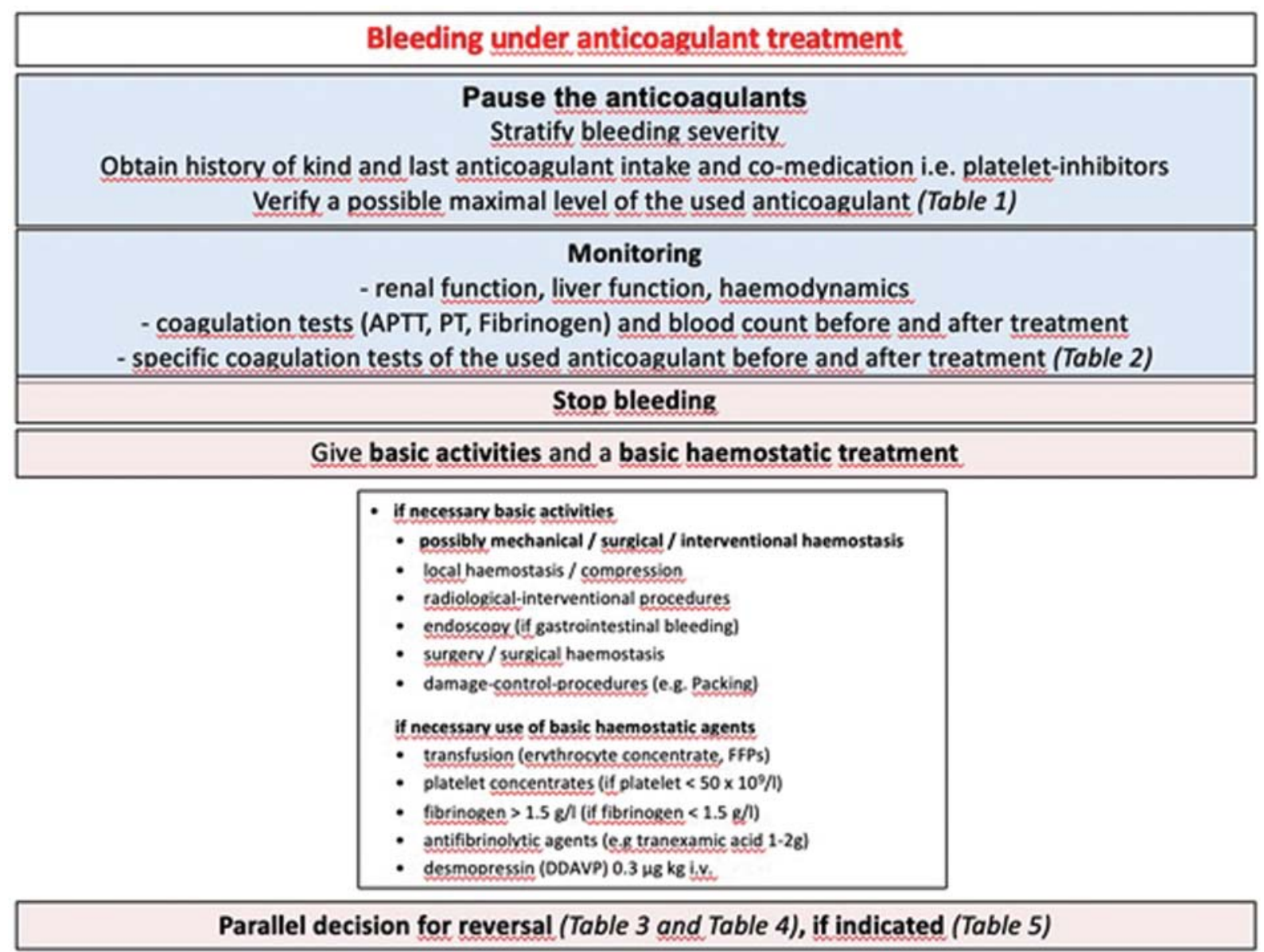

Fig. 1 Practical management of bleeding (modified from various studies ${ }^{3-9}$ ). APTT, activated partial thromboplastin time; FFP, fresh frozen plasma; i.v., intravenous; PT, prothrombin time.

strategy together with the interruption of the anticoagulant intake is advised. In cases of severe or life-threatening bleeding, however, hemostatic management needs to be encompassed by hemodynamic stabilization to avoid hemorrhagic shock and its consequences. For life-threatening bleeding, e.g., intracranial hemorrhage, predominantly a rapid, targeted, and advanced hemostasis management is required in addition to hemodynamic stabilization. ${ }^{3-9}$

Furthermore, adjunct treatments such as the administration of blood products and antifibrinolytics may be indicated depending on the extent of bleeding. The use of further procoagulants (e.g., tranexamic acid or desmopressin) may be considered, although valid data are lacking, ${ }^{3-9}$ as well as coagulation factor concentrates (e.g., fibrinogen) are indicated in hypofibrinogenemia only, as there is no specific effect of fibrinogen supplementation in anticoagulant-induced bleedings.

Life-threatening bleedings require the urgent decision for a reversal strategy of the used anticoagulant ( - Table 3 or -Table 4). - Table 5 shows the possible indications for the available reversal strategies. ${ }^{10-13}$ Activities for accelerated elimination or to reduce absorption are not useful in a case of emergency, urgent surgeries, or bleeding.

The therapy with other procoagulant concentrates as an activated PCC (e.g., factor eight inhibitor bypassing activity
[FEIBA]) or recombinant factor VIIa is not approved ${ }^{3-9}$ and has been investigated in in vitro or animal studies only. ${ }^{14-16}$ Sufficient clinical data for the efficacy and safety of this treatment approach are lacking, so that recommendations from international guidelines (e.g., European Heart Rhythm Association) require caution. ${ }^{17}$ The combined use of these products should be avoided due to the high risk of thromboembolic complications. The potential of this measure to achieve improved hemostasis remains doubtful due to its mode of action. ${ }^{10-13}$

\section{Procedure in Case of Urgent Surgeries}

Patients on anticoagulation who present with an urgent indication for surgery (e.g., acute bowel obstruction or appendicitis, paratonsillar abscess, etc.) require a hemostatic strategy. In these situations, surgery must be started regardless of the level of the anticoagulant level to prevent further deterioration or death of the patient. These pieces of crucial information need to be obtained and the following considerations should be made before the start of surgery (-Fig. 2, -Table 1):

- Which anticoagulant was taken?

- When was the last intake of the anticoagulant? 
Table 1 Basic pharmacological data of anticoagulants ${ }^{24}$

\begin{tabular}{|c|c|c|c|}
\hline Drug & Excretion & $\begin{array}{l}\text { Plasmatic } \\
\text { half-time } \\
\text { (maximal plasma } \\
\text { level time) }\end{array}$ & $\begin{array}{l}\text { Therapeutic drug } \\
\text { middle levels }\end{array}$ \\
\hline Phenprocoumon & $\begin{array}{l}\text { Hepatic metabolism } \\
\text { Inactive metabolites Renal }\end{array}$ & $\begin{array}{l}\text { ca. } 90-160 \mathrm{~h} \\
\text { (ca. } 50-72 \mathrm{~h})\end{array}$ & INR: $2.0-3.0$ \\
\hline Warfarin & $\begin{array}{l}\text { Hepatic metabolism } \\
\text { Inactive metabolites Renal }\end{array}$ & $\begin{array}{l}\text { ca. } 40 \mathrm{~h} \\
\text { (ca. } 18-22 \mathrm{~h})\end{array}$ & INR: $2.0-3.0$ \\
\hline Dabigatran & Renal ca. $80 \%$ & $\begin{array}{l}\text { ca. } 12-14 \mathrm{~h} \\
\text { (ca. } 4 \mathrm{~h})\end{array}$ & ca. $40-180 \mathrm{ng} / \mathrm{mL}$ \\
\hline Apixaban & $\begin{array}{l}\text { Renal approx. } 25 \% \\
\text { Hepatic approx. } 75 \%\end{array}$ & $\begin{array}{l}\text { ca. } 8-13 \mathrm{~h} \\
\text { (ca. } 4 \mathrm{~h})\end{array}$ & ca. $90-320 \mathrm{ng} / \mathrm{mL}$ \\
\hline Rivaroxaban & $\begin{array}{l}\text { Renal approx. } 25 \% \\
\text { Hepatic approx. } 75 \%\end{array}$ & $\begin{array}{l}\text { ca. } 5-13 \mathrm{~h} \\
\text { (ca. } 4 \mathrm{~h})\end{array}$ & ca. $90-320 \mathrm{ng} / \mathrm{mL}$ \\
\hline Edoxaban & $\begin{array}{l}\text { Renal approx. } 35 \% \\
\text { Hepatic approx. } 65 \%\end{array}$ & $\begin{array}{l}\text { ca. } 5-13 \mathrm{~h} \\
\text { (ca. } 4 \mathrm{~h})\end{array}$ & ca. $90-320 \mathrm{ng} / \mathrm{mL}$ \\
\hline UFH & $\begin{array}{l}\text { Rapid endothelial cell } \\
\text { internalization: } \\
\text { approx. } 40 \% \\
\text { slower renal clearance: approx. } 60 \%\end{array}$ & $\begin{array}{l}\text { ca. } 45-90 \mathrm{~min} \\
\text { (ca. } 60 \mathrm{~min} \text { ) }\end{array}$ & ca. $0.4-0.7$ anti-Xa IE/mL \\
\hline LMWHs & $\begin{array}{l}\text { Mainly renal- } \\
\text { dependent of molecular size }\end{array}$ & $\begin{array}{l}\text { ca. } 12-18 \mathrm{~h} \\
\text { (ca. } 4 \mathrm{~h})\end{array}$ & $\begin{array}{l}\text { ca. } 0.4-0.7 \text { anti-Xa IE } / \mathrm{mL} \\
\text { (twice daily) } \\
\text { ca. } 0.6-1.0 \text { anti-Xa IE } / \mathrm{mL} \\
\text { (once daily) }\end{array}$ \\
\hline Fondaparinux & Renal > 70\% & $\begin{array}{l}\text { ca. } 17-21 \mathrm{~h} \\
\text { (ca. } 4-6 \mathrm{~h})\end{array}$ & ca. $0.7-1.2$ anti-Xa IE/mL \\
\hline Danaparoid & Mainly renal & $\begin{array}{l}\text { ca. } 5-6 \mathrm{~h} \\
\text { (ca. } 2-3 \mathrm{~h})\end{array}$ & ca. $0.6-1.1$ anti-Xa IE/mL \\
\hline Argatroban & Hepatic $>70 \%$ & $\begin{array}{l}\text { ca. } 45 \mathrm{~min} \\
\text { (ca. } 20 \mathrm{~min} \text { ) }\end{array}$ & ca. $0.5-2.0 \mu \mathrm{g} / \mathrm{mL}$ \\
\hline Bivalirudin & Mainly renal & $\begin{array}{l}\text { ca. } 25 \mathrm{~min} \\
\text { (ca. } 10 \mathrm{~min} \text { ) }\end{array}$ & ca. $0.5-2.0 \mu \mathrm{g} / \mathrm{mL}$ \\
\hline
\end{tabular}

Abbreviations: IE, internationale eenheid; INR, international normalized ratio; LMWHs, low-molecular-weight heparins; UFH, unfractionated heparin.

Table 2 Preferred laboratory tests for the different anticoagulants to monitor reversal ${ }^{12,13,24-26,28,29}$

\begin{tabular}{|l|l|}
\hline Drug & Tests after reversal \\
\hline $\begin{array}{l}\text { Phenprocoumon, } \\
\text { warfarin }\end{array}$ & Prothrombin time (PT), INR \\
\hline Dabigatran & Diluted thrombin time (dTT) \\
\hline Apixaban & Calibrated chromogenic anti-Xa assays \\
\hline Rivaroxaban & Calibrated chromogenic anti-Xa assays \\
\hline Edoxaban & Calibrated chromogenic anti-Xa assays \\
\hline $\begin{array}{l}\text { Unfractionated } \\
\text { heparin (UFH) }\end{array}$ & $\begin{array}{l}\text { Calibrated chromogenic anti-Xa assays, } \\
\text { thrombin time (TT), APTT }\end{array}$ \\
\hline $\begin{array}{l}\text { Low-molecular-weight } \\
\text { heparins (LMWHs) }\end{array}$ & Calibrated chromogenic anti-Xa assays \\
\hline Fondaparinux & Calibrated chromogenic anti-Xa assays \\
\hline Danaparoid & Calibrated chromogenic anti-Xa assays \\
\hline Argatroban & Diluted thrombin time (dTT), APTT \\
\hline Bivalirudin & Diluted thrombin time (dTT), APTT \\
\hline
\end{tabular}

Abbreviations: APTT, activated partial thromboplastin time; INR, international normalized ratio.
- What is the assumed plasma level of used anticoagulant (peak or trough)?

- How is the kidney and/or liver function?

- Is there an additional risk of perioperative bleeding due to surgery?

A basic laboratory test and specific coagulation tests of the used anticoagulant before and after treatment may be helpful (-Table 2).

-Table 6 lists the relevant high-risk operations. Given the short half-life of most anticoagulants, it is expected that after peak levels, usually 2 to 4 hours after DOAC intake, with every hour the risk of bleeding decreases. For operations that are an urgent or emergent surgical indication, but also associated with an increased risk of bleeding (e.g., large wound area), the specific measurements of the particular anticoagulant may be included in the decision of the timing of surgery. Plasma concentrations $<30 \mathrm{ng} / \mathrm{mL}$ for DOACs may not require any hemostatic treatment before the start of surgery. ${ }^{18} \mathrm{At}$ plasma concentrations $\geq 30 \mathrm{ng} / \mathrm{mL}$, interventions/procedures may be deferred and, if necessary, monitored at 12- to 24-hour 
Table 3 Common specific agents used for reversal of anticoagulants

\begin{tabular}{|c|c|c|c|}
\hline Drug & Dose & Mechanism of action & Pharmacokinetics \\
\hline Vitamin $\mathrm{K}$ & 1-10 mg i.v./p.o. & $\begin{array}{l}\text { Acts as cofactor for hepatic synthesis } \\
\text { of clotting factors II, VII, IX, and X }\end{array}$ & $\begin{array}{l}\text { Onset of action: } 6-10 \mathrm{~h} \text { (p.o.), } \\
1-2 \mathrm{~h} \text { (i.v.); peak effect: } 24-48 \mathrm{~h} \\
\text { (p.o.), 12-14 h (i.v.) }\end{array}$ \\
\hline $\begin{array}{l}\text { Protamine } \\
\text { (sulfate) }\end{array}$ & $12.5-50 \mathrm{mg}$ i.v. & $\begin{array}{l}\text { Combines with heparin to neutralize } \\
\text { its anticoagulant activity }\end{array}$ & $\begin{array}{l}\text { Onset of action: } 5 \mathrm{~min} \text {; } \\
\text { duration of action: } 2 \mathrm{~h}\end{array}$ \\
\hline $\begin{array}{l}\text { Prothrombin } \\
\text { complex } \\
\text { concentrate }\end{array}$ & 25-50 IE/kg i.v. & $\begin{array}{l}\text { Contains vitamin K-dependent clotting } \\
\text { factors II, VII, IX, X as well as } \\
\text { protein C and S }\end{array}$ & $\begin{array}{l}\text { Rapid onset of action } \\
\text { (within minutes); half-life of } \\
\text { different factors is variable }\end{array}$ \\
\hline Idarucizumab & $\begin{array}{l}2 \times 2,5 \mathrm{~g} \text { i.v., maybe } \\
\text { repeated once }\end{array}$ & Binds to dabigatran and its metabolites & $\begin{array}{l}\text { Onset of action: } 10-30 \text { min; half-life: } \\
47 \text { min (initial) } 10 \mathrm{~h} \text { (terminal) }\end{array}$ \\
\hline Andexanet alfa & $\begin{array}{l}400-800 \mathrm{mg} \text { i.v. bolus } \\
\text { and then } 4-8 \mathrm{mg} / \mathrm{min} \\
\text { infusion }\end{array}$ & $\begin{array}{l}\text { Binds to and reverses the effects of } \\
\text { oral factor Xa inhibitors } \\
\text { (rivaroxaban, apixaban) }\end{array}$ & $\begin{array}{l}\text { Effect within minutes after } \\
\text { beginning of infusion and lasts } \\
\text { for the duration of infusion }\end{array}$ \\
\hline
\end{tabular}

Abbreviations: IE, internationale eenheid; i.v., intravenous; LMWH, low-molecular-weight heparin; p.o., per oral.

Table 4 Use of protamine derivatives in $\mathrm{LMWH}^{47,48}$

\begin{tabular}{|c|c|}
\hline Active drug & $\begin{array}{l}1 \text { mg protamine sulfate } \\
\text { or hydrochloride } \\
\text { (100 antiheparin units) } \\
\text { neutralizes: }\end{array}$ \\
\hline - Certoparin-sodium & - 200 anti-Xa IU certoparin \\
\hline - Dalteparin-sodium & - 100 IE, anti-Xa IU dalteparin \\
\hline - Enoxaparin-sodium & $\begin{array}{l}\text { - } 1 \text { mg (100 anti-Xa IU) } \\
\text { enoxaparin }\end{array}$ \\
\hline - Nadroparin-calcium & - 160 anti-Xa IU nadroparin \\
\hline - Reviparin-sodium & - 82 anti-Xa IU reviparin \\
\hline - Tinzaparin-sodium & - 100 anti-Xa IU tinzaparin \\
\hline
\end{tabular}

Abbreviation: IE, internationale eenheid; IU, international unit; LMWH, low-molecular-weight heparin.

intervals. ${ }^{9-13}$ Emergency surgery may also need to be performed under effective levels of anticoagulants. In these situations, the different reversal strategies ( - Table 3 or - Table 4 ) for the respective different anticoagulants are indicated (-Table 5).

In addition to specific hemostatic or reversal treatment, surgical hemostasis needs to be diligently applied as well as nonspecific hemostatic measures may be helpful (e.g., tranexamic acid, desmopressin in the case of additional aspirin intake, maintenance of $\mathrm{pH}$, and normothermia).

Due to the risk of thromboembolism and the not finally proven proof of efficacy, prophylactic administration of factor concentrates should be discouraged. An experienced surgical and anesthesia team and a sufficient stock of blood products and coagulation factor concentrates should be available in the operation room. Hemostatic drugs such as tranexamic acid and desmopressin may support hemostasis. Depending on the localization of bleeding (bleeding into a vital organ), surgery may be started without a prophylactic administration of factor concentrates and PCC can be given when bleeding cannot be controlled surgically. Apart from clinical signs of bleeding, monitoring and maintenance of mean arterial pressure (target: $65 \mathrm{~mm} \mathrm{Hg}$ ) is crucial.
A combination of specific reversal agents with PCCs should be avoided, whenever possible.

\section{Procedure in Case of Overdosing of Anticoagulant without Bleeding}

Generally, in case of an overdose of anticoagulants, conducting coagulation tests may help to estimate the risk of bleeding. In case of excessive anticoagulation, the treatment with anticoagulants must be paused. ${ }^{3-13}$

After acute ingestion of large doses of VKA in the first 24 hours in humans, a toxic effect to cerebral capillaries with brain edema is in the foreground. After that, there is an increase in international normalized ratio (INR) and intracranial bleeding as the worst adverse reaction of anticoagulant treatment may occur. Recognizable signs of an acute overdose, depending on their extent, can be hematuria, petechial bleeding in places of mechanical pressure, spontaneous skin and mucosal bleeding, bloody stools, confusional states to unconsciousness, etc. ${ }^{3,4}$ Therefore, depending on the severity of bleeding, a graded reversal concept for overdose of VKA using vitamin $\mathrm{K}$ and 25 to $50 \mathrm{IU} / \mathrm{kg}$ PCCs is indicated (- Table 5 ). ${ }^{19}$

To reduce the absorption in case of factor Xa inhibitor overdose, the use of activated charcoal within 2 to 6 hours after last intake may be considered. ${ }^{20-22}$ A reversal strategy is not indicated unless severe bleeding occurs. ${ }^{3,4}$ In case of dabigatran overdose, a sufficient diuresis must be ensured, since the drug is mainly excreted renally. General supportive measures such as the use of activated charcoal to reduce absorption may be considered. A reversal strategy is not indicated unless bleeding occurs. ${ }^{9}$

For all heparins (unfractionated heparin [UFH], low-molecular-weight heparin [LMWH]), fondaparinux and danaparoid can be summarized: overdose rarely leads to clinically significant bleeding, although severe retroperitoneal bleeds have been described in patients with renal insufficiency. ${ }^{23}$ Waiting for the maximum effect subsided after 2 to 4 hours and control of bleeding is usually sufficient. In mild bleeds waiting for the plasma levels to decrease after the peak levels 
Table 5 Possible indications for use of available reversal strategies $^{10-13}$

\begin{tabular}{|c|}
\hline In a case of serious bleeding: \\
\hline - Dabigatran > $50 \mathrm{ng} / \mathrm{mL}$ \\
\hline - Apixaban > $50 \mathrm{ng} / \mathrm{mL}$ \\
\hline - Rivaroxaban > $50 \mathrm{ng} / \mathrm{mL}$ \\
\hline - Edoxaban > $50 \mathrm{ng} / \mathrm{mL}^{\mathrm{a}}$ \\
\hline $\begin{array}{l}\text { - Phenprocoumon, warfarin-no specific levels (target } \\
\text { level }<1.4 \text { ) }\end{array}$ \\
\hline $\begin{array}{l}\text { - UFH, LMWH (fondaparinux }{ }^{\text {a }} \text {-no specific levels (target } \\
\text { level }<0.1 \mathrm{IU} / \mathrm{mL} \text { ) }\end{array}$ \\
\hline $\begin{array}{l}\text { In a case of urgent surgery with a high risk of bleeding } \\
(- \text { Table } 6) \text { : }\end{array}$ \\
\hline - Dabigatran > $30 \mathrm{ng} / \mathrm{mL}$ \\
\hline - Apixaban > $30 \mathrm{ng} / \mathrm{mL}$ \\
\hline - Rivaroxaban > 30 ng/mL \\
\hline - Edoxaban > $30 \mathrm{ng} / \mathrm{mL}^{\mathrm{a}}$ \\
\hline $\begin{array}{l}\text { - Phenprocoumon, warfarin-no specific levels (target } \\
\text { level }<1.4 \text { ) }\end{array}$ \\
\hline $\begin{array}{l}\text { - UFH, LMWH (fondaparinux }{ }^{a} \text { )-no specific levels (target } \\
\text { level }<0.1 \mathrm{IU} / \mathrm{mL} \text { ) }\end{array}$ \\
\hline In a case of stroke requiring thrombolysis ${ }^{\mathrm{b}}$ : \\
\hline - Dabigatran > $50 \mathrm{ng} / \mathrm{mL}$ \\
\hline - Apixaban > $10 \mathrm{ng} / \mathrm{mL}$ \\
\hline - Rivaroxaban > $100 \mathrm{ng} / \mathrm{mL}$ \\
\hline - Edoxaban $>50 \mathrm{ng} / \mathrm{mL}^{\mathrm{a}}$ \\
\hline - Phenprocoumon, warfarin: INR > 1.7 \\
\hline - UFH, LMWH (fondaparinux ${ }^{\mathrm{a}}$ )-no specific levels \\
\hline In a case of overdose without bleeding: \\
\hline $\begin{array}{l}\text { - Phenprocoumon, warfarin: INR }>10 \text { or INR } 4.5-10 \text { and } \\
\text { risk factor for bleeding }\end{array}$ \\
\hline (see - Table 7) \\
\hline
\end{tabular}

Abbreviations: INR, international normalized ratio; LMWH, low-molecular-weight heparin; UFH, unfractionated heparin.

Note: Caveat-in the case of life-threatening bleeding (e.g., intracranial bleeding, or in emergency surgery for life-threatening conditions such as a ruptured aortic aneurysm), reversal of the anticoagulant effect should not be delayed while awaiting test results!

a Data in progress.

${ }^{\mathrm{b}}$ The cut-off values are based on expert-panel opinions and not yet recommended by the German neurology guidelines.

has been reached at 2 to 4 hours after injection and, if necessary, mechanical control of bleeding is usually sufficient. A reversal strategy is not indicated unless severe bleeding occurs. ${ }^{9}$

For the thrombin inhibitors argatroban or bivalirudin, excessive anticoagulation with or without bleeding can usually be controlled by discontinuation or reducing the rate of infusion due to the low plasma half-life of these drugs (approximately 50 and 25 minutes, respectively). Appropriate laboratory markers for these anticoagulants (diluted thrombin time [dTT] or Ecarin clotting time [ECA]) decline to baseline within 1 to 4 hours after cessation of argatroban or bivalirudin in clinical trials and in our experience. ${ }^{9}$

\section{Management of VKA and DOACs in a Case of Stroke Requiring Thrombolysis}

Patients on VKA who develop an ischemic stroke and requiring thrombolysis can be treated with thrombolytic therapy up to an INR of 1.7. Overlying INR values are an indication for a reversal strategy ( - Table 5 ). For the rare case that patients treated with UFH, LMWH, or fondaparinux develop a stroke while being fully anticoagulated, there are no such validated thresholds for thrombolysis. Therapeutic doses of UFH and LMWH can be completely partially be reversed, although clinical experiences are very limited.

In ischemic stroke requiring thrombolysis, plasma concentrations of 10 (apixaban) ng/mL, 50 (dabigatran) ng/mL, and 100 (rivaroxaban) ng/mL have been proposed as cut-offs for considering intravenous thrombolysis with recombinant tissue plasminogen activator after an individual risk-benefit assessment (- Table 5). ${ }^{10-13}$ The cut-off values are based on expert-panel opinions and not yet recommended by the German neurology guidelines.

\section{Coagulation Tests under Anticoagulation}

Routine coagulation tests (activated partial thromboplastin time [APTT] and prothrombin time [PT] or the PT ratio, "Quick value") do not allow an exact quantification of the anticoagulant effect of most agents, and only the INR is recommended and regularly used for the monitoring of VKA. ${ }^{13,24}$

Currently, no available coagulation test can precisely predict the risk of bleeding. Often, merely the pharmacokinetics and a "snapshot" of the plasma anticoagulant level allow the determination of the level of anticoagulation. For the interpretation of coagulation tests, it is crucial to know the time of last anticoagulant intake as well.

For all bleeding events related to anticoagulation, the type of anticoagulant, the dose and time of last intake, and kidney and liver functions need to be determined after evaluation of bleeding predictors to estimate the level of the respective anticoagulant. $^{10-13,24-26}$

Plasma levels of the thrombin inhibitors dabigatran, argatroban, and bivalirudin can be estimated using dTT, whereas calibrated chromogenic anti-Xa assays are used to determine the anticoagulatory effect of direct and indirect factor $\mathrm{Xa}$ inhibitors (apixaban, edoxaban, rivaroxaban, LMWH, fondaparinux, danaparoid, and even UFH) ${ }^{10-13,24-26}$ (- Table 2).

\section{Monitoring Tests for Thrombin Inhibitors (Dabigatran, Argatroban, and Bivalirudin)}

The thrombin time (TT) reacts highly sensitively to even very low levels of dabigatran, argatroban, and bivalirudin, so that a $\mathrm{dTT}$ is required that almost linearly correlates with increasing plasma concentrations of the thrombin inhibitors. ${ }^{10,12,13,26}$ However, the actual measured value of the TT is highly dependent on the coagulometer and the amount of thrombin 


\section{Urgent surgeries under anticoagulant treatment}

\section{Pause the anticoaqulants}

Obtain history of kind and last anticoagulant intake and co-medication i.e. platelet-inhibitors Verify a possible maximal level of the used anticoagulant (Table 1)

Verify a possible high procedural risk of bleeding (Table 6)

\begin{tabular}{|c|}
\hline $\begin{array}{l}\text { Monitoring } \\
\text { - renal function, liver function, haemodynamics } \\
\text { - coagulation tests (APT, PT, Fibrinogen) and blood count before and after treatment } \\
\text { - specific coagulation tests of the used anticoagulant before and after treatment (Table 2) }\end{array}$ \\
\hline Give basic perioperative activities and a basic haemostatic treatment \\
\hline
\end{tabular}

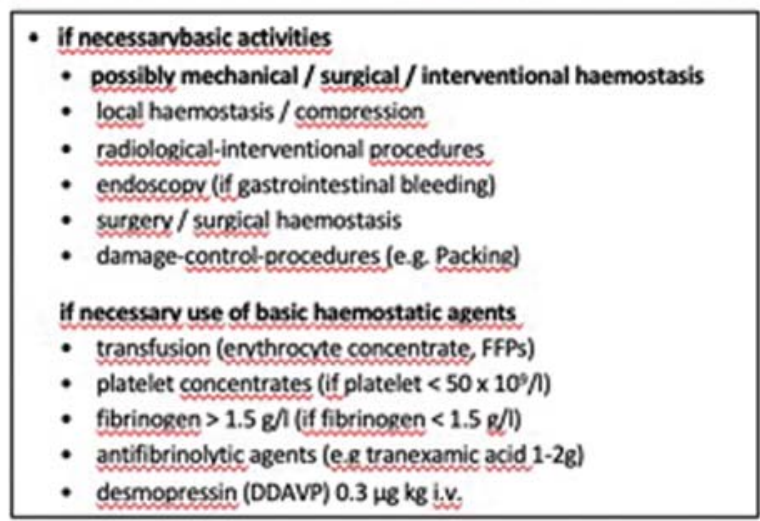

\section{Parallel decision for reversal (Table 3 and Table 4), if indicated (Table 5)}

Fig. 2 Practical management of urgent surgeries under anticoagulant (modified from various studies ${ }^{3-9}$ ). APTT, activated partial thromboplastin time; FFP, fresh frozen plasma; i.v., intravenous; PT, prothrombin time.

Table 6 High procedural risk of bleeding (>2\% 2nd-day risk of severe bleeding)

\begin{tabular}{|l|}
\hline - Major vascular surgery (e.g., intestinal anastomosis) \\
\hline $\begin{array}{l}\text { - Major orthopaedic surgery (hip/knee replacement, spinal } \\
\text { surgery) }\end{array}$ \\
\hline - Major tumor surgery including tumor debulking \\
\hline $\begin{array}{l}\text { - Cardiac surgery (e.g., conventional valve surgery, coro- } \\
\text { nary artery bypass surgery) }\end{array}$ \\
\hline - Neurosurgery \\
\hline - Epidural anesthesia \\
\hline
\end{tabular}

Source: Modified from Douketis et al. ${ }^{57}$

used for the measurement. Due to the high sensitivity, the TT may be used as a screening assay for thrombin inhibitors. The rarely available ECT allows a direct measurement and quantification of the effect of the direct thrombin inhibitors and may be a reliable alternative. The ECT is also sensitive to very low levels of the thrombin inhibitors, and normal levels are only observed with complete absence of dabigatran, argatroban, and bivalirudin.

If the dose and time of the last intake of the thrombin inhibitors are unknown, normal values for the APTT and TT
Table 7 Risk factors for recurrent $\mathrm{ICH}$ and severe bleedings $56,57,66,67$

\begin{tabular}{|l|}
\hline - Large area ICH \\
\hline - ICH history \\
\hline - Lobar ICH location \\
\hline - Cerebral microbleeds \\
\hline - Amyloid angiopathy \\
\hline - Arteriovenous malformation \\
\hline - Cerebral aneurysm \\
\hline - Lacunar infarcts \\
\hline - Leukoaraiosis \\
\hline - Asian population \\
\hline - Alcohol abuse \\
\hline - Severe hepatic disease \\
\hline - Severe renal dysfunction \\
\hline - High risk of fall \\
\hline
\end{tabular}

Abbreviation: $\mathrm{ICH}$, intracerebral hemorrhage.

exclude clinically relevant anticoagulant concentrations of dabigatran, argatroban, and bivalirudin, so that further measurements of the ECT and dTT do not need to be performed. 


\section{Tests for Factor Xa Inhibitors (Apixaban, Edoxaban, and Rivaroxaban)}

Calibrated chromogenic anti-Xa assays should be used to assess the plasma levels of the factor Xa inhibitors (apixaban, edoxaban, and rivaroxaban), but require calibration with substance-specific reagents. ${ }^{10-13,24-29}$ There is no calibration standard available for the emergency situation. A normal antifactor Xa activity in the plasma (with or without specific calibration, e.g., anti-factor Xa activity for LMWH) signals the lack of significant factor Xa inhibitor levels.

After intake of factor Xa inhibitors, parallel to peak levels after 2 to 4 hours, a prolongation of the APTT of 1.2 to 1.6 -fold or a reduction of the PT ratio ("Quick value") (PT prolongation) by approximately two times compared with the baseline values can be observed.

According to the Subcommittee on Control of Anticoagulation of the International Society on Thrombosis and Hemostasis (ISTH) on the use of specific antidotes for the reversal of DOACs, a drug concentration $>30 \mathrm{ng} / \mathrm{mL}$ in patients requiring an urgent procedure associated with a high risk of bleeding warrants antidote administration, whereas in patients with major bleeding, antidote administration should be considered if the drug concentration exceeds $50 \mathrm{ng} / \mathrm{mL}^{10,28}$ However, delaying the intervention or the administration of an antidote until normalization of coagulation test results is not possible in the case of life-threatening bleeding (e.g., intracranial bleeding or in emergency surgery for life-threatening conditions such as a ruptured aortic aneurysm) and reversal of the anticoagulant effect must not be delayed while awaiting test results.

In less urgent clinical scenarios, the use of specific coagulation tests may also help to document the normalization of coagulation after administration of the antidote or to guide the use of the antidote.

\section{Test for Vitamin K Antagonists}

The laboratory analysis of the effect of VKA is done specifically via the PT-derived INR..$^{10-13,24-26}$ The INR is only valid in patients in the "steady state" of anticoagulation with VKA, because problems with the comparability of the results may occur especially of these patients. Therefore, an INR should be ordered only when the Quick value is decreased or the PT is extended, as this may be correlated to the dose of VKA.

Generally, there is no precise correlation between INR and major bleeding. Therefore, signs of bleeding (black stool, urine staining, increased hematoma, bleeding nose or gums, and sudden headache as a possible first sign of intracerebral hemorrhage $[\mathrm{ICH}]$ ) need to be monitored independently of INR values.

\section{Tests for UFH, LMWH, Fondaparinux, and Danaparoid}

For effective heparinization, it is desirable to extend the upper limit of APTT standard range to 1.5 to 2.5 times in the responsible laboratory (always taking into account the same laboratory values, as the results differ with different test reagents). Under clinical conditions, only approximately $40 \%$ of patients treated with heparins reach the target ranges. Due to the thrombin-binding effect of UFH, the additional determination of TT may be valuable for estimating the anticoagulant effect of UFH. Calibrated chromogenic anti-Xa assays determine the UFH effect more precisely. This should also be used in the case of bleeding, overdosage, or even before planned reversals of UFH.

For LMWHs, calibrated chromogenic anti-Xa assays are the appropriate tests to assess the effect of LMWH, fondaparinux, and danaparoid. There is no correlation between the results of these calibrated anti-Xa assays and the risk of bleedings. ${ }^{13,24,27,28}$

\section{The Different Anticoagulants and Different Reversal Strategies}

\section{Reversal of Vitamin K Antagonists}

Vitamin $K_{1}$ (phytomenadione) is used to antagonize the effect of VKA (warfarin, phenprocoumon, and acenocoumarol). It should be noted that the onset of the anticoagulant effect of VKAs is delayed and the plasma half-lives of VKA are different. After oral administration of VKAs, a decrease in the INR can be expected at the earliest after 6 hours, and after intravenous infusion of vitamin $\mathrm{K}$, the effect occurs more rapidly ( - Table 2 ).

Intravenous or oral vitamin $\mathrm{K}$ can reverse the effect of VKAs within 12 to 48 hours and is indicated for any bleeding or an INR $>10$ or 4.5 to 10 in patients with additional risk factors for bleeding. ${ }^{30-32}$ Due to an increased risk of anaphylactoid reactions and fat embolism (oily solution), slow intravenous infusion is indicated.

If the application of vitamin $\mathrm{K}$ is fast enough or not sufficiently effective in the case of life-threatening bleeding related to VKA, the administration of prothrombin complex preparations (usually four-factor PCC) is indicated. ${ }^{17-20}$ PCC contains the vitamin-K-dependent coagulation factors II, VII, IX, and $X$ as well as protein $C$ and protein $S$ and abolishes the anticoagulant effect of VKA within 30 minutes. ${ }^{19}$ The usual dosage of PCC is 25 to 50 international unit (IU)/ $/ \mathrm{kg}$ (ca. 2,000-4,000 IU). One IU PCC per kilogram of body weight leads to an increase in the "Quick value" by approximately 1 to $2 \%$, the factors VII and IX by 0.5 to $1.0 \%$, and the factors II and $\mathrm{X}$ by 1.0 to $2.0 \%$. The effect of the VKA reversal may be documented using the PT, PT ratio, or INR within 30 to 60 minutes after PCC application.

PCC is to be used in combination with vitamin $\mathrm{K}$ because the effect of PCC is rapid but persists for a short time only, so vitamin $\mathrm{K}(5-10 \mathrm{mg})$ is needed to maintain synthesis of coagulation factors with a short half-life (FVII: 5-6 hours). The thrombotic risk of PCC is small $(\approx 0.1 \%)$, but must not be neglected in the cohort of patients requiring anticoagulant treatment. Commercially available PCC factor concentrates differ in the concentration of coagulation factors ${ }^{28}$ as they are standardized for their factor IX content only. PCC factor concentrates may contain heparin or antithrombin and must not be used in patients with a history of heparin-induced thrombocytopenia type II (HIT II) within the last 120 days., ${ }^{4,5}$ 


\section{Reversal of Dabigatran}

Idarucizumab is the only and especially developed and approved direct reversal agent for dabigatran. ${ }^{3-9,33,34}$ This monoclonal antibody fragment binds with picomolar binding affinity to free and thrombin-bound dabigatran and its metabolites. The anticoagulant effect of dabigatran is almost completely reversed by two subsequent short infusions of 2.5 g idarucizumab for approximately 12 hours. ${ }^{21}$ The terminal half-life of idarucizumab is approximately 10 hours. It is approved in patients who have severe and uncontrollable bleeding on treatment with dabigatran or prior to acute procedures/surgeries. This may comprise the scenario of thrombolytic therapy in the case of an acute stroke as well. There are no known drug interactions, and there are no contraindications because of its high clinical safety. The time to cessation of extracranial bleeding is 2.5 hours after the abolishment of dabigatran-induced anticoagulation. The risk of thrombosis after 30 days is between 4 and $5 \%$ in patients with acute bleeding. The reversing effect of idarucizumab can be reliably verified by dTT.

In addition, dabigatran can be removed by hemodialysis or hemadsorption. This might be considered additional measures in patients without bleeding despite very high levels, or in acute or chronic renal failure. ${ }^{35}$

An administration of activated PCC with $50 \mathrm{IU} / \mathrm{kg}$ of body weight has been investigated but its effect is inferior to idarucizumab and no more recommended. ${ }^{3-9}$

\section{Reversal of Apixaban and Rivaroxaban}

The factor Xa inhibitor reversal agent andexanet alfa is the only available direct factor Xa-inhibitor antidote to date, but is under further clinical testing ${ }^{36}$ still. However, the European Medicines Agency (EMA) granted market approval for andexanet alfa in May 2019, with restrictions (further postauthorization studies for safety and efficacy also for other anticoagulants), for the reversal of rivaroxaban- and apixaban-induced bleeding, but not edoxaban or other factor Xa inhibitors.

Andexanet alfa is a recombinant and modified version of human activated coagulation factor $\mathrm{X}$ without factor $\mathrm{Xa}$ enzymatic activity. It binds directly factor Xa inhibitors with the same affinity as the natural factor Xa, which leads to the competitive inhibition of the anticoagulant with antifactor Xa activity (DOACs, but also fondaparinux, LMWH, and in past UFH). For anticoagulants that are not factor Xa inhibitors, andexanet alfa is ineffective.

Andexanet alfa simultaneously binds to tissue factor pathway inhibitors (TFPIs) and inhibits the activity of TFPI for 10 to 20 hours after administration. This further reduces the effect of anticoagulants. ${ }^{37,38}$ The clinical relevance and possible thromboembolic potential of this interaction with regard to the maintenance of thrombin formation is to be further investigated (see conditions of the EMA 2019).

The safety of andexanet alfa was investigated in 352 patients and its efficacy in 167 patients in a noncontrolled investigation $^{38}$ (similar to idarucizumab, 34). Currently, there are not sufficient data for admission without restrictions. ${ }^{36-38}$ Due to the short plasma half-life of approximately 1 hour, andexanet alfa is given as a bolus followed by a continuous infusion; the maximum decrease in the concentration of unbound factor Xa inhibitor, e.g., apixaban or rivaroxaban, occurs rapidly (within 2 minutes after the end of bolus administration) and remains present during the continuous infusion. After the end of the infusion, the anticoagulant concentration may gradually increase again and reach a maximum approximately 2 hours after the end of the infusion.

The recommended and approved dose regimen of andexanet alfa is based on the dose of apixaban or rivaroxaban taken by the patient at the time the anticoagulation was withdrawn, as well as the time since the last intake of apixaban or rivaroxaban. ${ }^{36-38}$ The bolus dose of andexanet alfa is given intravenously at a target infusion rate of approximately $30 \mathrm{mg} / \mathrm{min}$ for 15 (400 mg: low dose) or 30 minutes (800 mg: high dose), followed immediately by a continuous infusion over 120 minutes with a rate of $4 \mathrm{mg} / \mathrm{min}$ ( $480 \mathrm{mg}$ : low dose) or $8 \mathrm{mg} / \mathrm{min}$ (960 mg: high dose). The low dose of andexanet alfa is used with:

- An intake of apixaban (dose-independent) greater than 8 hours.

- A last dose of apixaban less than $5 \mathrm{mg}$ (time-independent).

- An intake of rivaroxaban (dose-independent) greater than 8 hours.

- A last dose of rivaroxaban less than $10 \mathrm{mg}$ (timeindependent).

The high dose of andexanet alfa is used with:

- A last dose of apixaban greater than $5 \mathrm{mg}$ or not known and/or intake less than 8 hours or not known.

- A last dose of rivaroxaban greater than $10 \mathrm{mg}$ or not known and/or intake less than 8 hours or not known.

The anti-factor-Xa activity shows an unclear correlation with the clinical efficacy and safety of andexanet alfa and, therefore, is not suitable for the determination of its dosage. In the ANNEXA-4 study, $10.3 \%$ of patients experienced thromboembolic events in the first 30 days after use. ${ }^{37,38}$ The use of andexanet alfa during pregnancy and in women of childbearing age who do not prevent pregnancy is not recommended. In cases of urgent surgery without bleeding, only PCC is still available as a nonspecific reversal agent for patients taking apixaban or rivaroxaban. ${ }^{3-9,39}$

\section{Nonspecific Reversal of Edoxaban}

Andexanet alfa as a factor Xa inhibitor reversal agent is still under further clinical testing for the reversal of edoxaban. Here, according to the manufacturer and the approval authorities, such as the U.S. Food and Drug Administration (FDA) or EMA, only PCC at a dosage ca. 25 to $50 \mathrm{IU} / \mathrm{kg}$ has been investigated ${ }^{40}$ and is currently recommended for nonspecific reversal during bleeding or urgent operations, ${ }^{3-9}$ when no direct antidote is available. To date, no prospective randomized trials have been conducted to demonstrate a confirmed effect of PCC on hemostasis in bleeding associated with DOACs (apixaban, rivaroxaban, and edoxaban). However, additional register data have been published worldwide, which show partial effectiveness but no clear proof of efficacy. ${ }^{39,41,42}$ 


\section{Reversal of Unfractionated Heparins}

For UFH, protamine sulfate and hydrochloride are available as reversal agents, allowing complete neutralization. One mg of protamine sulfate or hydrochloride neutralizes $100 \mathrm{IU}$ UFH. ${ }^{43,44}$ Patients who have been pretreated with protamine sulfate or hydrochloride or insulin containing protamine, as well as those with a fish protein allergy or prior vasectomy, have a higher risk of an anaphylactic reaction. To avoid these reactions, protamine sulfate or hydrochloride should be administered slowly to predisposed patients, preferably as a slow-drip infusion in 100 to $200 \mathrm{~mL}$ of physiological saline over 10 minutes. Rapid application may also result in a significant drop in blood pressure due to the release of histamine from mast cells. The effect of protamine sulfate or hydrochloride occurs rapidly within 5 minutes.

Through complement activation, even pulmonary hypertension can be triggered, which can cause considerable problems, such as right ventricular failure especially in patients during heart surgery. Ideally, the reversal dose should be defined by the coagulation status and clinical bleeding situation to avoid overdosage. Otherwise, an overapplied dose of protamine (-sulfate or -chloride) can induce or trigger new bleeding complications, ${ }^{3-6,44-46}$ of which, however, the underlying pathophysiology is not fully understood yet.

\section{Reversal of Low-Molecular-Weight Heparins}

The neutralization of LMWHs by protamine sulfate or chloride is incomplete only in terms of their anticoagulant effect. - Table 3 shows different degrees of neutralization by protamine sulfate or chloride ( - Table 3 ). It almost completely neutralizes the anti-factor Ila activity of LMWH, whereas the anti-Xa activity is only partially neutralized. ${ }^{47,48}$ The content of sulfate groups and the molecular weight are the major determinants for the extent of the neutralization of different LMWHs by protamine.

Protamine derivatives act as anticoagulants when overdosed and can thus induce bleeding. Therefore, an adequate dosage has to be exactly determined. ${ }^{3-6}$

After reaching the maximum level of LMWH, approximately 3 to 4 hours after subcutaneous administration, the dose of protamine to be administered should take into account:

- The half-life of the LMWH.

- Reduction by $10 \%$ for every hour that has elapsed.

The length of the absorption phase at the injection site may cause further LMWH entrance to the circulation (the so-called "depot effect"). ${ }^{47,48}$ In these cases, repeated use or even a continuous infusion of protamine may be necessary.

Andexanet alfa is currently undergoing clinical trials to reverse the anticoagulant effect of the LMWH enoxaparin. ${ }^{36}$

\section{Nonspecific Reversal for Fondaparinux}

A reversal agent that allows rapid inactivation of fondaparinux is currently not available. ${ }^{49}$ Andexanet alfa is currently undergoing clinical evaluation for this indication. ${ }^{36}$ Protamine, as a classic reversal agent for heparins, is ineffective as its effect depends on the molecular weight of the heparin molecule.
Appropriate measures in cases of overdosage of fondaparinux and bleeding symptoms include mechanical hemostasis, replacement of blood components and supportive measures. For severe bleeding, nonspecific measures such as fresh frozen plasma (FFP) transfusion are recommended, and plasmapheresis may be considered as well. However, in individual cases, a bolus of recombinant activated factor VII at a dose of approximately $100 \mu \mathrm{g} / \mathrm{kg}$ in combination with $1,000 \mathrm{mg}$ tranexamic acid (intravenous) has been shown to reduce clotting times and termination of bleeding. ${ }^{3-6,49-51}$

\section{No Available Reversal of Danaparoid}

An antidote that allows the rapid neutralization of danaparoid is currently unavailable. ${ }^{52}$ Despite a partial effect on its anticoagulant effect, the administration of protamine to reverse danaparoid is not recommended. Nonspecific measures, such as the use of FFP, can be used to treat bleeding. If severe bleeding cannot be controlled, plasmapheresis should be considered. ${ }^{3-6,52}$ Whether hemabsorption using the Cytosorb filter may substantially reduce danaparoid levels in the plasma or andexanet alfa has the potential to directly reverse the anti-factor-Xa effect of danaparoid is unclear and requires further investigation.

\section{No Available Reversal of Argatroban and Bivalirudin} A specific reversal agent for neither $\operatorname{argatroban}^{53}$ nor bivalirudin is currently not available. However, bivalirudin can be removed by hemodialysis. ${ }^{54,55}$ Both anticoagulants have a very short plasma half-life which may, in clinical practice, reduce the need for direct reversal strategies. General hemostatic measures aiming at reducing the blood loss are indicated in cases of hemodynamically relevant bleedings or bleeds requiring transfusions. ${ }^{3-6,53-56}$

\section{Restart the Anticoagulants after Bleeding or Surgery with High Risk of Bleeding}

Resumption of oral or parenteral anticoagulants is important for the patients at high risk of thromboembolism, such as those with prosthetic mechanical valve, high risk of pulmonary embolism (PE), and atrial fibrillation (AF) patients with a high $\mathrm{CHA}_{2} \mathrm{DS}_{2}$-VASc scores (congestive heart failure, hypertension, age $\geq 75$ years, type 2 diabetes, previous stroke/transient ischemic attack/thromboembolism, vascular disease, age 65 to 74 years, and gender category), i.e., $\mathrm{CHA}_{2} \mathrm{DS}_{2}$-VASc score $\geq 4$ (57-60). In patients in whom resumption of therapeutic anticoagulation (usually achieved by oral anticoagulants) is not an option, e.g., after recurrent ICH and other bleeds (- Table 7), left atrial appendage occlusion in patients with $\mathrm{AF}$ and vena cava filter in patients with deep-vein thrombosis and PE is a reasonable alternative to reduce thromboembolic risk.

After surgery with a high risk of hemorrhage and a certain period of immobilization, the time interval until resumption must be checked individually until DOACs are restarted. Prerequisite is a secured hemostasis and wound drainages having been removed, which should be achieved within 48 to 72 hours.

In patients with a high risk of thrombosis (venous thrombosis $<3$ months, with or without PE, recurrent idiopathic 
thrombosis as well as AF and cardioembolic events), a switch to LMWH at a prophylactic dose (high risk) for a few days (e.g., 2-5 days) may be useful. Basically, after hemostasis is restored, pharmacological prophylaxis can be started with LWWH at the earliest 6 to 8 hours after the procedure and at least 48 to 72 hours after the previous DOAC intake. For traumatic intracranial hemorrhages or epi- and subdural hematomas, the resumption of anticoagulation after 4 weeks is recommended. ${ }^{57}$

\section{Conclusions and Perspectives}

With some exceptions, only a limited number of reversal agents and valid (rapid) test systems exist for emergency bleedings associated with the use of anticoagulants. ${ }^{10-13,24-26,28,29}$ While heparins are mainly used in health care facilities, DOACs are increasingly used in the outpatient setting and are associated with a lower risk of intracranial and other life-threatening bleeding than VKA. ${ }^{2,7,58}$ Concomitant renal and hepatic impairment increase the accumulation risk of most anticoagulants. ${ }^{3-9}$ If possible, surgical interventions should be postponed according to the known half-life after the last intake of anticoagulant. ${ }^{3-9}$ The elapsed time after the last application and the residual concentration of an anticoagulant are also relevant in cases of bleeding or urgent surgery. Anticoagulation should be stopped immediately, and local measures should be taken to stop the bleeding. In the case of life-threatening bleeding or emergency surgery, the anticoagulant effect should be stopped immediately and hemostatic treatment algorithms should be followed. Idarucizumab is approved as a specific reversal agent for dabigatran only. ${ }^{34,59}$ Andexanet alfa, which acts as a reversal agent for the factor $\mathrm{X}$ inhibitors apixaban and rivaroxaban, has recently been approved with restrictions. ${ }^{60}$ For other anticoagulant agents, such as fondaparinux, enoxaparin, or edoxaban, the collection of clinical data and approval studies of andexanet alfa are still ongoing. ${ }^{36}$ Protamine derivatives reverse the effect of UFH and, partially, of LMWH ${ }^{44,47}$ immediately, while intravenous or oral vitamin $\mathrm{K}$ reverses the effects of VKA after a lag time of 12 to 24 hours. PCCs are used as specific and fast-acting reversal agents in cases of major bleeding associated with VKA. ${ }^{31}$

Apart from pharmacological and even surgical measures to secure hemostasis, in severe bleedings the advice of experts in thrombosis and hemostasis should be sought to inform clinicians on adequate monitoring as well as safe and effective treatment.

After intracranial bleeding, an INR $\leq 1.3$ with a blood pressure reduction $<160 \mathrm{~mm} \mathrm{Hg}$ within 4 hours is associated with a smaller increase of intracranial hematoma. ${ }^{61}$

PCC should be preferred in situations in which a specific reversal agent is not available. While administration of PCC appears to be effective in promoting adequate hemostasis, activated PCC or activated factor VII concentrate should be used only if all other measures have not led to adequate control of bleeding, as data are restricted and these agents have stronger procoagulant effects than PCC. ${ }^{42,62-64}$
All approval studies for the specific reversal agents idarucizumab and andexanet alfa are only one-arm cohort studies without a comparator arm. ${ }^{34,36}$ The actual hemostatic efficacy compared with placebo or nonspecific reversal agents has not been studied. An up-to-date meta-analysis provides an initial indication that intracranial cerebral hemorrhage related to DOAC may be more clinically effective if the specific reversal agents are used compared with nonspecific hemostatic activities. ${ }^{65}$ For all other anticoagulants, there are no comparative data on intracranial bleeding.

Conflicts of Interest

Adj. Prof. Dr.J. Koscielny declares the following conflicts of interest: speaker honoraria from Aspen, Bayer Health Care Pharmaceuticals, Biotest, Chugai, Daiichi Sankyo, Boehringer Ingelheim, CSL Behring, Pfizer, LFB, BMS, Mitsubishi, Roche, Sanofi, Novo Nordisk, and Shire (Takeda). Adj. Prof. Dr. Koscielny is also a medical advisor for CSL Behring International, Bayer HealthCare Pharmaceuticals (national and international), and Novo Nordisk (national).

Dr. E. Rutkauskaite has no conflict of interest regarding the publication of this article.

Adj. Prof. Dr. C. Sucker received honoraria for travel reimbursements, lectures, and consultancy work related to the topic of this article from Aspen, CSL Behring, DOASENSE, Chugai, Mitsubishi Pharma, Novo Nordisk, Novartis, Roche, Sanofi, and Werfen during the last 3 years.

Prof. Dr. C. von Heymann received research grants, honoraria for travel reimbursements, lectures, and consultancy work related to the topic of this article from Bayer Pharma GmbH, Biotest GmbH, BMS, CSL Behring, Daiichi Sankyo Europe, HICC GbR, Novo Nordisk Pharma GmbH, Pfizer $\mathrm{GmbH}$, and Takeda during the last 3 years.

\section{References}

1 Stahmann MA, Hübner CF, Link KP. Studies on the hemorrhagic sweet clover disease identification and synthesis of the hemorrhagic agent. J Biol Chem 1941;138(02):513-527

2 Czuprynska J, Patel JP, Arya R. Current challenges and future prospects in oral anticoagulant therapy. $\mathrm{Br} \mathrm{J}$ Haematol 2017; 178(06):838-851

3 Makris M, Van Veen JJ, Tait CR, Mumford AD, Laffan M; British Committee for Standards in Haematology. Guideline on the management of bleeding in patients on antithrombotic agents. Br J Haematol 2013;160(01):35-46

4 Hunt BJ, Allard S, Keeling D, Norfolk D, Stanworth SJ, Pendry K; British Committee for Standards in Haematology. A practical guideline for the haematological management of major haemorrhage. Br J Haematol 2015;170(06):788-803

5 Koscielny J, Rutkauskaite E. Bleedings under NOAC (non vitamin-K dependent oral anticoagulants). Evidence and practical management [in German]. Hamostaseologie 2015;35(Suppl 1):S43-S53

6 Frontera JA, Lewin JJ III, Rabinstein AA, et al. Guideline for reversal of antithrombotics in intracranial hemorrhage: a statement for healthcare professionals from the Neurocritical Care Society and Society of Critical Care Medicine. Neurocrit Care 2016;24(01):6-46

7 Albaladejo P, Samama CM, Sié P, et al; GIHP-NACO Study Group. Management of severe bleeding in patients treated with direct oral anticoagulants: an observational registry analysis. Anesthesiology 2017;127(01):111-120 
8 Koscielny J, Rosenthal C, von Heymann C. Bleeding management under direct oral anticoagulants (DOAC) [in German]. Dtsch Med Wochenschr 2018;143(24):1734-1738

9 Eikelboom JW, Kozek-Langenecker S, Exadaktylos A, et al. Emergency care of patients receiving non-vitamin $\mathrm{K}$ antagonist oral anticoagulants. Br J Anaesth 2018;120(04):645-656

10 Levy JH, Ageno W, Chan NC, Crowther M, Verhamme P, Weitz JI; Subcommittee on Control of Anticoagulation. When and how to use antidotes for the reversal of direct oral anticoagulants: guidance from the SSC of the ISTH. J Thromb Haemost 2016;14 (03):623-627

11 Douketis JD, Spyropoulos AC, Duncan J, et al. Perioperative management of patients with atrial fibrillation receiving a direct oral anticoagulant. JAMA Intern Med 2019;179(11):1469-1478

12 Douxfils J, Ageno W, Samama C-M, et al. Laboratory testing in patients treated with direct oral anticoagulants: a practical guide for clinicians. J Thromb Haemost 2018;16(02):209-219

13 Keeling D, Tait RC, Watson H; British Committee of Standards for Haematology. Perioperative management of anticoagulation and antiplatelet therapy. Br J Haematol 2016;175:602-613

14 Marlu R, Hodaj E, Paris A, Albaladejo P, Cracowski JL, Pernod G. Effect of non-specific reversal agents on anticoagulant activity of dabigatran and rivaroxaban: a randomised crossover ex vivo study in healthy volunteers. Thromb Haemost 2012;108(02): 217-224

15 Körber MK, Langer E, Ziemer S, Perzborn E, Gericke C, Heymann $\mathrm{Cv}$. Measurement and reversal of prophylactic and therapeutic peak levels of rivaroxaban: an in vitro study. Clin Appl Thromb Hemost 2014;20(07):735-740

16 Godier A, Miclot A, Le Bonniec B, Durand M, Lecompte T, Samama $\mathrm{CM}$. Evaluation of prothrombin complex concentrate and recombinant activated factor VII to reverse rivaroxaban in a rabbit model. Eur J Anaesthesiol 2011;28:1-9

17 Steffel J, Verhamme P, Potpara TS, et al; ESC Scientific Document Group. The 2018 European Heart Rhythm Association Practical Guide on the use of non-vitamin K antagonist oral anticoagulants in patients with atrial fibrillation: executive summary. Europace 2018;20(08):1231-1242

18 Godier A, Dincq AS, Martin AC, et al. Predictors of pre-procedural concentrations of direct oral anticoagulants: a prospective multicentre study. Eur Heart J 2017;38(31):2431-2439

19 Pabinger I, Brenner B, Kalina U, Knaub S, Nagy A, Ostermann H; Beriplex P/N Anticoagulation Reversal Study Group. Prothrombin complex concentrate (Beriplex $\mathrm{P} / \mathrm{N}$ ) for emergency anticoagulation reversal: a prospective multinational clinical trial. J Thromb Haemost 2008;6(04):622-631

20 Wang X, Mondal S, Wang J, et al. Effect of activated charcoal on apixaban pharmacokinetics in healthy subjects. Am J Cardiovasc Drugs 2014;14(02):147-154

21 Sajkov D, Gallus A. Accidental rivaroxaban overdose in a patient with pulmonary embolism: some lessons for managing new oral anticoagulants. Clin Med Insights Case Rep 2015;8:57-59

22 Jourdi G, Delrue M, Stepanian A, et al. Potential usefulness of activated charcoal (DOAC remove ${ }^{\circledR}$ ) for $\mathrm{dRVVT}$ testing in patients receiving direct oral anticoagulants. Thromb Res 2019;184: 86-91

23 Lim W, Dentali F, Eikelboom JW, Crowther MA. Meta-analysis: low-molecular-weight heparin and bleeding in patients with severe renal insufficiency. Ann Intern Med 2006;144(09): 673-684

24 Kitchen S, Gray E, Mackie I, Baglin T, Makris M; BCSH Committee. Measurement of non-coumarin anticoagulants and their effects on tests of haemostasis: guidance from the British Committee for Standards in Haematology. Br J Haematol 2014;166(06):830-841

25 Guy S, Kitchen S. Maclean R, Van Veen JJ. Limitation of the activated partial thromboplastin time as a monitoring method of the direct thrombin inhibitor argatroban. Int J Lab Hematol 2015;37(06):834-843
26 Cuker A, Siegal DM, Crowther MA, Garcia DA. Laboratory measurement of the anticoagulant activity of the non-vitamin $\mathrm{K}$ oral anticoagulants. J Am Coll Cardiol 2014;64(11):1128-1139

27 Spyropoulos AC, Al-Badri A, Sherwood MW, Douketis JD. To measure or not to measure direct oral anticoagulants before surgery or invasive procedures: comment. J Thromb Haemost 2016;14(12):2556-2559

28 Gosselin RC, Adcock DM, Bates SM, et al. International Council for Standardization in Haematology (ICSH) recommendations for laboratory measurement of direct oral anticoagulants. Thromb Haemost 2018;118(03):437-450

29 Funk DM. Coagulation assays and anticoagulant monitoring. Hematology (Am Soc Hematol Educ Program) 2012;2012(01):460-465

30 Patriquin C, Crowther M. Treatment of warfarin-associated coagulopathy with vitamin K. Expert Rev Hematol 2011;4(06):657-665, quiz 666-667

31 Brekelmans MPA, Ginkel KV, Daams JG, Hutten BA, Middeldorp S, Coppens M. Benefits and harms of 4-factor prothrombin complex concentrate for reversal of vitamin $\mathrm{K}$ antagonist associated bleeding: a systematic review and meta-analysis. J Thromb Thrombolysis 2017;44(01):118-129

32 Hunt BJ, Levi M. Urgent reversal of vitamin K antagonists. BMJ 2018;360:j5424

33 Schiele F, van Ryn J, Canada K, et al. A specific antidote for dabigatran: functional and structural characterization. Blood 2013;121(18):3554-3562

34 Pollack CV Jr, Reilly PA, van Ryn J, et al. Idarucizumab for dabigatran reversal - full cohort analysis. N Engl J Med 2017; 377(05):431-441

35 Khadzhynov D, Wagner F, Formella S, et al. Effective elimination of dabigatran by haemodialysis. A phase I single-centre study in patients with end-stage renal disease. Thromb Haemost 2013; 109(04):596-605

36 Ondexxya. Available at: https://www.ema.europa.eu/en/documents/ product-information/ondexxya-epar-product-information_de.pdf. Accessed June 30, 2019

37 Connolly SJ, Milling TJ Jr, Eikelboom JW, et al; ANNEXA-4 Investigators. Andexanet alfa for acute major bleeding associated with factor Xa inhibitors. N Engl J Med 2016;375(12):1131-1141

38 Connolly SJ, Crowther M, Eikelboom JW, et al; ANNEXA-4 Investigators. Full study report of andexanet alfa for bleeding associated with factor Xa inhibitors. N Engl J Med 2019;380(14): 1326-1335

39 Majeed A, Ågren A, Holmström M, et al. Management of rivaroxaban- or apixaban-associated major bleeding with prothrombin complex concentrates: a cohort study. Blood 2017;130(15): 1706-1712

40 Zahir H, Brown KS, Vandell AG, et al. Edoxaban effects on bleeding following punch biopsy and reversal by a 4 -factor prothrombin complex concentrate. Circulation 2015;131(01):82-90

41 Piran S, Khatib R, Schulman S, et al. Management of direct factor Xa inhibitor-related major bleeding with prothrombin complex concentrate: a meta-analysis. Blood Adv 2019;3(02):158-167

42 Schulman S, Gross PL, Ritchie B, et al; Study Investigators. Prothrombin complex concentrate for major bleeding on factor Xa inhibitors: a prospective cohort study. Thromb Haemost 2018; 118(05):842-851

43 Juergens CP, Semsarian C, Keech AC, Beller EM, Harris PJ. Hemorrhagic complications of intravenous heparin use. Am J Cardiol 1997;80(02):150-154

44 Kortchinsky T, Vigué B, Samama CM. Reversal for heparins and new anticoagulant treatments [in French]. Ann Fr Anesth Reanim 2013;32(01):37-49

45 Koster A, Börgermann J, Gummert J, Rudloff M, Zittermann A, Schirmer U. Protamine overdose and its impact on coagulation, bleeding, and transfusions after cardiopulmonary bypass: results of a randomized double-blind controlled pilot study. Clin Appl Thromb Hemost 2014;20(03):290-295 
46 Meesters MI, Veerhoek D, de Lange F, et al. Effect of high or low protamine dosing on postoperative bleeding following heparin anticoagulation in cardiac surgery. A randomised clinical trial. Thromb Haemost 2016;116(02):251-261

47 Crowther MA, Berry LR, Monagle PT, Chan AK. Mechanisms responsible for the failure of protamine to inactivate low-molecular-weight heparin. Br J Haematol 2002;116(01):178-186

48 Schroeder M, Hogwood J, Gray E, Mulloy B, Hackett AM, Johansen KB. Protamine neutralisation of low molecular weight heparins and their oligosaccharide components. Anal Bioanal Chem 2011; 399(02):763-771

49 Desmurs-Clavel H, Huchon C, Chatard B, Negrier C, Dargaud Y. Reversal of the inhibitory effect of fondaparinux on thrombin generation by rFVIIa, aPCC and PCC. Thromb Res 2009;123(05):796-798

50 Bijsterveld NR, Moons AH, Boekholdt SM, et al. Ability of recombinant factor VIIa to reverse the anticoagulant effect of the pentasaccharide fondaparinux in healthy volunteers. Circulation 2002;106(20):2550-2554

51 Huvers F, Slappendel R, Benraad B, van Hellemondt G, van Kraaij M. Treatment of postoperative bleeding after fondaparinux with rFVIIa and tranexamic acid. Neth J Med 2005;63(05):184-186

52 Danaparoid Sodium. Eur Pharmacop 2006

53 Swan SK, Hursting MJ. The pharmacokinetics and pharmacodynamics of argatroban: effects of age, gender, and hepatic or renal dysfunction. Pharmacotherapy 2000;20(03):318-329

54 Warkentin TE, Greinacher A, Koster A. Bivalirudin. Thromb Haemost 2008;99(05):830-839

55 Beyer JT, Lind SE, Fisher S, et al. Evaluation of intravenous direct thrombin inhibitor monitoring tests: correlation with plasma concentrations and clinical outcomes in hospitalized patients. J Thromb Thrombol 2019;49(02):259-267

56 Sié P, Samama CM, Godier A, et al; Working Group on Perioperative Haemostasis; French Study Group on Thrombosis and Haemostasis. Surgery and invasive procedures in patients on longterm treatment with direct oral anticoagulants: thrombin or factor-Xa inhibitors. Recommendations of the Working Group on Perioperative Haemostasis and the French Study Group on
Thrombosis and Haemostasis. Arch Cardiovasc Dis 2011;104(12): 669-676

57 Douketis JD, Spyropoulos AC, Spencer FA, et al. Perioperative management of antithrombotic therapy: Antithrombotic Therapy and Prevention of Thrombosis, 9th ed: American College of Chest Physicians Evidence-Based Clinical Practice Guidelines. Chest 2012;141(2 Suppl):e326S-e350S

58 Lincoff AM, Mehran R, Povsic TJ, et al; REGULATE-PCI Investigators. Effect of the REG1 anticoagulation system versus bivalirudin on outcomes after percutaneous coronary intervention (REGULATE-PCI): a randomised clinical trial. Lancet 2016;387(10016): 349-356

59 Levy JH, Douketis J, Weitz JI. Reversal agents for non-vitamin K antagonist oral anticoagulants. Nat Rev Cardiol 2018;15(05):273-281

60 Lu G, DeGuzman FR, Hollenbach SJ, et al. A specific antidote for reversal of anticoagulation by direct and indirect inhibitors of coagulation factor Xa. Nat Med 2013;19(04):446-451

61 Kuramatsu JB, Gerner ST, Schellinger PD, et al. Anticoagulant reversal, blood pressure levels, and anticoagulant resumption in patients with anticoagulation-related intracerebral hemorrhage. JAMA 2015;313(08):824-836

62 Dickneite G, Hoffman M. Reversing the new oral anticoagulants with prothrombin complex concentrates (PCCs): what is the evidence? Thromb Haemost 2014;111(02):189-198

63 Piran S, Khatib R, Schulman S, et al. Management of direct factor Xa inhibitor-related major bleeding with prothrombin complex concentrate: a meta-analysis. Blood Adv 2019;3(02):158-167

64 Grottke O, Levy JH. Prothrombin complex concentrates in trauma and perioperative bleeding. Anesthesiology 2015;122(04):923-931

65 Katsanos AH, Schellinger PD, Köhrmann M, et al. Fatal oral anticoagulant-related intracranial hemorrhage: a systematic review and meta-analysis. Eur J Neurol 2018;25(10):1299-1302

66 Lai A, Davidson N, Galloway SW, Thachil J. Perioperative management of patients on new oral anticoagulants. Br J Surg 2014;101 (07):742-749

67 Li YG, Lip GYH. Anticoagulation resumption after intracerebral hemorrhage. Curr Atheroscler Rep 2018;20(07):32-34 